\title{
Chinese government reaffirms backing for GM products
}

To the Editor:

This year's 'No. 1 Central Document' (NCD) - a document issued every January by the Chinese Communist Party's Central Committee and the State Council-states explicitly that China will put more resources into R\&D on genetically modified (GM) products and into public education surrounding these products so as to regain the country's position as a global leader in the area. Genetic modification has been discussed six times in the annual NCD between 2007 and 2015. Here we survey NCDs from 2007 to 2015 and infer that the top leadership's opinion shifted like a pendulum toward GM technology, and then away in the face of public opposition - and now back again.

In 2007, the NCD announced an intention to implement a GM food labeling system. It was followed by the "Mandatory Labeling of GM Food" policy released by China's Ministry of Agriculture in 2007 (ref. 1). In 2008, the NCD started national research projects to cultivate new varieties of transgenic organisms. This was also followed by a National Science and Technology Major Project (NSTMP) program (released by China's Ministry of Science and Technology in 2008) to invest about 24 billion yuan ( $\$ 3.9$ billion) in developing GM technologies from 2008 to 2020. In 2009 and 2010, the two NCDs proposed to accelerate the transgenic NSTMP program ${ }^{2}$. And in 2009, the Biosafety Committee of China's Ministry of Agriculture issued biosafety licenses for two crops, rice and corn ${ }^{3}$. This policy evolution-from asserting the need for labeling of GM products to concerted investment in the GM NSTMP program and regulatory approvals raised expectations that China might become a leader in commercializing GM rice and corn ${ }^{1,2}$.

However, in the years following 2009, public resistance to GM products grew. And in China, public opinion often has a powerful influence in steering government policy in areas that are less politically controversial. For example, in the late 2000s, public environmental protests were instrumental in persuading local government officials to cancel construction of a billion-dollar chemical plant and a trash incinerator project ${ }^{4}$. Such environmental activism has also induced officials to disclose more environmental information ${ }^{5}$. As in the West, public concerns about GM food safety are widespread. According to the Blue Book of Public Opinion Survey in China, only 0.9\% of the respondents fully accept GM food ${ }^{6}$. In this context, the political neutrality of GM policy has meant that public safety concerns have trumped GM policy to the extent that a protechnology stance in the early 2000s was almost entirely reversed by 2010 . Thus, from 2011 to 2014 , the NCD failed to mention GM products at all. And the NCD in 2014 even neglected to use the term "GM," preferring instead the euphemism "molecular breeding."

We contend that this political stalemate regarding GM products-reflected in the NCDs-has set back transgenic R\&D in China and turned the country from being one of the world's proponents of the technology to one of the most conservative developers. Between 1997 and 2001, China encouraged the planting of insect-resistant GM cotton and was the fourth largest GM crop grower globally. In 2014, China, with 3.9 million hectares of GM crops, ranked sixth in the world behind India (with 11.6 million hectares of GM crops) $)^{7}$. And in 2013, research funding for GM seed cultivation programs fell to around 400 million yuan ( $\sim 65$ million), down from as much as 2 billion yuan in 2010 (ref. 8).

In this context, we believe that the 2015 NCD represents an important shift in government policy. It indicates a restatement of interest by the Central Committee and State Council in GM technology, which augurs well for R\&D projects on GM products. It remains to be seen how fast this renewed political backing can be translated into a return of national funding into this important research area.

COMPETING FINANCIAL INTERESTS

The authors declare no competing financial interests. Rongrong Li ${ }^{1}$, Qiang Wang
Alan McHughen

${ }^{1}$ School of Business Administration, Xinjiang University of Finance and Economics, Urumqi, Xinjiang, P.R. China. ${ }^{2}$ Xinjiang Institute of Ecology and Geography, CAS, Urumqi, P.R. China. ${ }^{3}$ China University of Petroleum (East China), Qingdao, P.R. China. ${ }^{4}$ Department of Botany \& Plant Sciences, University of California-Riverside, California, USA. e-mail:qiangwang7@outlook.com

1. Qiu, J. Natl. Sci. Rev. 1, 466-470 (2014).

2. Wang, Q. Nature 519, 7 (2015)

3. Quu, J. Nature $455,850-852$ (2008).

4. Wang, Q. Science 328, 824 (2010)

5. Wang, Q. Nature 497, 159 (2013).

6. Xie, G.-Y. Blue Book of Public Opinion Surveys in China (Social Science Academic Press, Shanghai, China, 2014).

7. Clive, J. ISAAA brief No. 49 (2014).

8. Shuping, N. \& Stanway, D. Reuters http://www.reuters. com/article/2014/03/10/china-parliament-gmoidUSL3NOM41FR20140310 (10 March 2015).

\section{Increased bioavailable vitamin $\mathrm{B}_{6}$ in field-grown transgenic cassava for dietary sufficiency}

\section{To the Editor:}

Vitamin $B_{6}$ deficiency is associated with cardiovascular disease, diabetes, neurological diseases ${ }^{1}$ and nodding syndrome (NS, a childhood condition in eastern Africa ${ }^{2}$ ). Pyridoxal 5'-phosphate (PLP), the cofactor form of vitamin $B_{6}$, is required for multiple essential enzymatic reactions and other forms of vitamin $B_{6}$, such as pyridoxine and pyridoxamine, inhibit oxygen radical production, pathogenic glycation and lipid peroxidation ${ }^{3,4}$. Notably, investigation of the causes of NS has revealed a high prevalence of vitamin $\mathrm{B}_{6}$ deficiencies in affected African populations $s^{2,5,6}$. Humans cannot synthesize vitamin $\mathrm{B}_{6}$ de novo, so this micronutrient is obtained from food by intestinal absorption ${ }^{7}$. In this Correspondence, we report biofortification of cassava Manihot esculenta Crantz with vitamin $\mathrm{B}_{6}$ using transgenes from Arabidopsis thaliana.

Cassava is a staple root crop for more than 250 million people in $\mathrm{Africa}^{8}$, including regions in which vitamin $B_{6}$ deficiency is endemic ${ }^{6}$. In addition to the plant's starchy roots, cassava leaves are also consumed as a 